\title{
Unique coincidence of ovarian and tubal teratoma
}

\author{
M. N. Baumgarten • G. Mestdagh
}

Received: 24 April 2011 / Accepted: 7 May 2011 /Published online: 24 May 2011

(C) Springer-Verlag 2011

An extremely rare coincidence, never described before, of an ovarian and tubal teratoma.

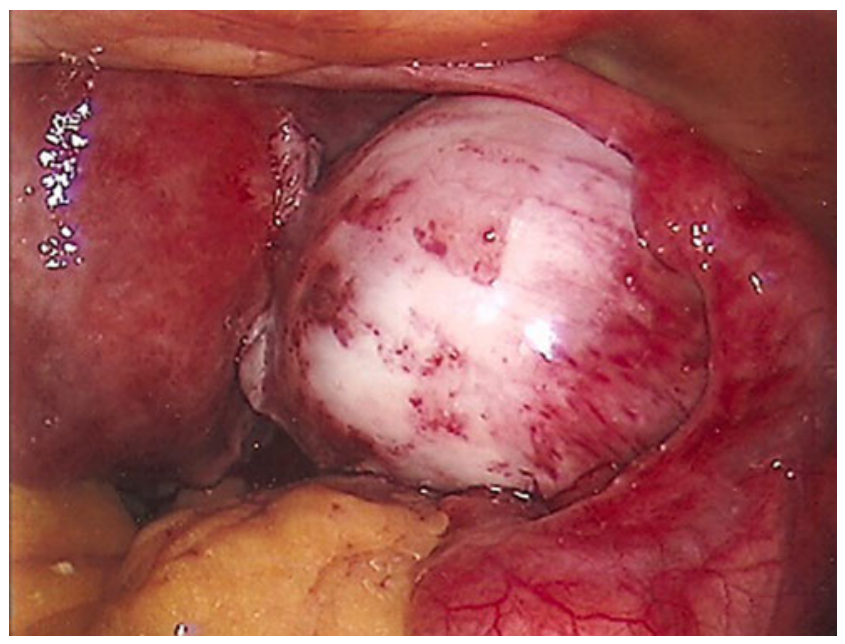

Figure 1: Laparoscopy in a 34-year-old woman shows an enlarged right ovary. A preoperative ultrasound was suggestive of a teratoma. The history of the patient included a laparoscopy at the age of 23 years for a hemorrhagic corpus luteum cyst on her right side. Since then, she had used the oral contraceptive pill. After opening of the ovarian cortex, the cyst was removed.

M. N. Baumgarten · G. Mestdagh

Department of Obstetrics and Gynecology,

Hospital East Limburg,

Genk, Belgium

M. N. Baumgarten $(\bowtie)$

Schiepse Bos 6,

3600 , Genk, Belgium

e-mail: miriambaumgarten@hotmail.com

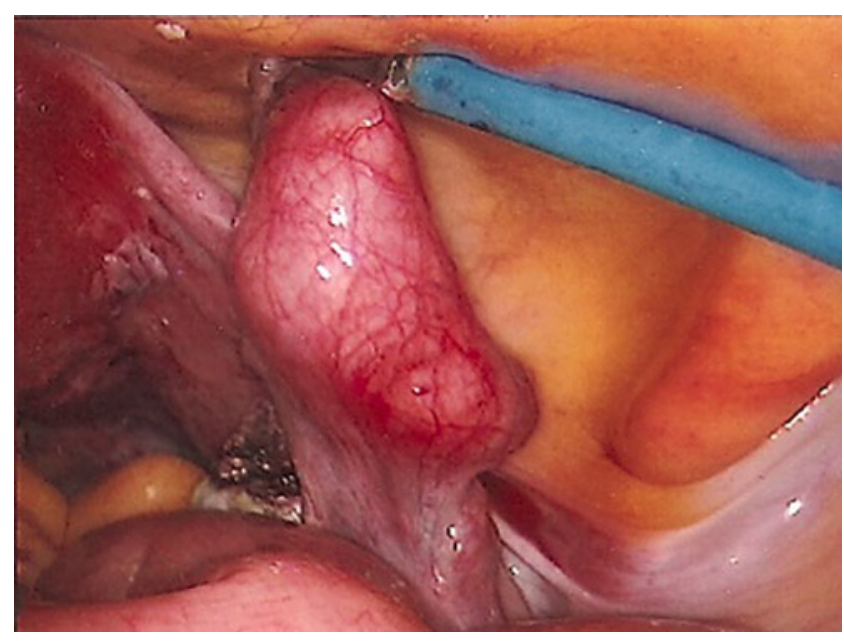

Figure 2: Further inspection showed distension of the right tuba. As the cause was unknown and tubal functionality was doubtful, a salpingectomy was performed.

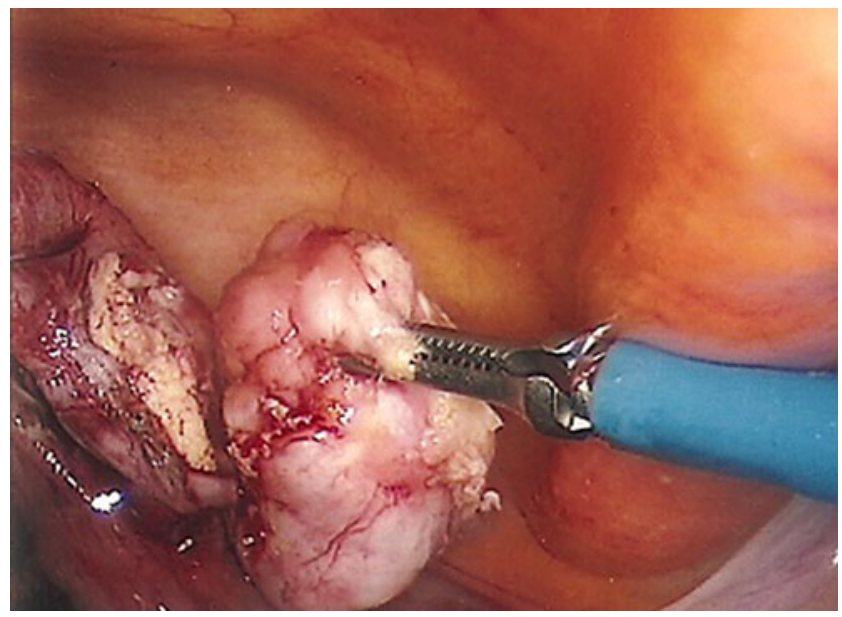

Figure 3: A cystic tumour was removed from the right tube. On histological investigation, the tumours were diagnosed as respectively an ovarian and tubal mature cystic teratoma

Declaration of interest The authors report no conflicts of interest. The authors alone are responsible for the content and writing of the paper. 